\title{
Midazolam protects B35 neuroblastoma cells through Akt- phosphorylation in reactive oxygen species derived cellular injury
}

\author{
Won Seog Chong ${ }^{1}$, Chang Lim Hyun², Min Kyu Park ${ }^{3}$ Jeong Min Park ${ }^{4}$, Hyun-Ouk Song ${ }^{5}$, Taejin Park ${ }^{6}$, \\ Young Su Lim ${ }^{4}$, Choon Kyu Cho ${ }^{4}$, Po Soon Kang ${ }^{4}$, and Hee Uk Kwon ${ }^{4}$ \\ ${ }^{1}$ Department of Pharmacology, College of Medicine, Seonam University, Namwon, ${ }^{2}$ Department of Pathology, School of Medicine \\ and Institute of Medical Science, Jeju National University, Jeju, ${ }^{3}$ Department of Chemical, Biological and Radiological Research, \\ Korean Armed Forces Medical Research Institute, ${ }^{4}$ Department of Anesthesiology and Pain Medicine, College of Medicine, Konyang \\ University, Daejeon, ${ }^{5}$ Department of Parasitology, Catholic University of Daegu School of Medicine, Daegu, ${ }^{6}$ Department of Surgery, \\ Seoul National University Hospital, Seoul, Korea
}

Background: Soman, a potent irreversible acetylcholinesterase (AChE) inhibitor, induces delayed neuronal injury by reactive oxygen species (ROS). Midazolam is used in patients with pathologic effects of oxidative stresses such as infection, hemodynamic instability and hypoxia. We investigated whether midazolam protects the Central Nervous System (CNS) from soman intoxication. The present study was performed to determine whether midazolam protects B35 cells from ROS stress for the purpose of exploring an application of midazolam to soman intoxication.

Methods: Glucose oxidase (GOX) induced ROS stress was used in a B35 neuroblastoma cell model of ROS induced neuronal injury. To investigate the effect of midazolam on cell viability, LDH assays and fluorescence activated cell sorting (FACS) analysis was performed. Western blotting was used for evaluating whether Akt-phosphorylation is involved in cell-protective effects of midazolam.

Results: GOX derived ROS injury decreased cell viability about 1.6-2 times compared to control; midazolam treatment ( 5 and $10 \mu \mathrm{g} / \mathrm{ml}$ ) dose-dependently increased cell viability during ROS injury. On western blots, Aktphosphorylation was induced during pretreatment with midazolam; it was diminished during co-treatment with LY294002, an inhibitor of Akt-phosphorylation. FACS analysis confirmed that the cell protective effect of midazolam is mediated by an anti-apoptotic effect. GOX-induced apoptosis was inhibited by midazolam and the finding was diminished by LY-294002.

Conclusions: Midazolam protects neuronal cells from GOX-induced ROS injury; this effect is mediated by an antiapoptotic effect through Akt-phosphorylation. This shows that midazolam may be useful in soman intoxication. (Korean J Anesthesiol 2012; 62: 166-171)

Key Words: Akt-phosphorylation, Midazolam, Reactive oxygen species (ROS), Soman.

Received: July 8, 2011. Revised: August 30, 2011. Accepted: September 21, 2011.

Corresponding author: Hee Uk Kwon, M.D., Ph.D., Department of Anesthesiology and Pain Medicine, College of Medicine, Konyang University, 685, Gasuwon-dong, Seo-gu, Daejeon 302-718, Korea. Tel: 82-42-600-9317, Fax: 82-42-545-2132, E-mail: gangsi@kyuh.ac.kr

(c) This is an open-access article distributed under the terms of the Creative Commons Attribution Non-Commercial License (http:// creativecommons.org/licenses/by-nc/3.0/), which permits unrestricted non-commercial use, distribution, and reproduction in any medium, provided the original work is properly cited. 


\section{Introduction}

Among nerve agents, soman is a major threat partly because of the serial toxicologic events following exposure to this nerve agent. It is a potent irreversible acetylcholinesterase (AChE) inhibitor in the cholinergic nervous system, which can produce serial toxic effects [1]. Reactive oxygen species (ROS) derived neuronal injury is one of the main mechanisms of delayed neuronal injury caused by soman. Intoxication with sublethal to lethal doses of soman causes convulsive seizures and seizure-related brain damage which are mediated by ROS production.

ROS derived from hydrogen peroxide $\left(\mathrm{H}_{2} \mathrm{O}_{2}\right)$, superoxide $\left(\mathrm{O}_{2}\right)$, and peroxynitrite (ONOO) are highly reactive and can lead to cell injury [2]. The injured cells exhibit serious responses such as inflammation and programmed cell death (e.g. apoptosis). Apoptosis is explained by controlled auto-degradation of cells and plays important roles in many biological processes including cellular damage, tumorigenesis, and teratogenicity [3]. Alternatively, to protect cells from damage induced by oxidative stress, cells have anti-oxidant defense systems and survivalpromoting pathways. The rapid activation or induction of protective enzymes which decrease oxidative stress by reducing ROS increases the capacity of cells to maintain homeostasis during oxidative stress; activation of survival-promoting pathways allow cells to tolerate and/or to recover from the damage [4]. Therefore, modulating these anti-oxidative defense systems and survival pathways may influence ROS derived cell injury.

Midazolam, a benzodiazepine derivative, is the most widely used anesthetic for sedation. It is also used in critically ill patients who usually suffer from the pathologic effects of oxidative stress such as infection, hemodynamic instability and hypoxia $[5,6]$. Several lines of evidences support an interaction between midazolam and ROS. Midazolam interferes with the synthesis and release of nitric oxide and tumor necrosis factor- $\alpha$ (TNF- $\alpha$ ) generated by activated immune cells [7] and inhibits neutrophil apoptosis in the perioperative periods. This suggests that midazolam may modulate inflammatory cellular injury.

Through studies of the anti-inflammatory effects of midazolam, we hoped to support the idea that midazolam can protect the Central Nervous System (CNS) from soman intoxication. However, it was necessary to first determine whether midazolam activates cell protective mechanisms that are involved in soman derived neural cell injury. Therefore, the aim of the present study was to explore the hypothesis that midazolam protects B35 neuroblastoma cells from ROS stress through activation of survival-promoting pathways such as antiapoptotic signaling.

\section{Materials and Methods}

\section{Materials}

Dulbecco's modified Eagle's medium (DMEM), fetal bovine serum (FBS), penicillin, streptomycin, trypsin/EDTA and glutamine were supplied by Gibco-BRL (Rockville, MD, USA). ECL western blotting detection reagents and PRO-PREP protein extract solution were supplied by iNtRON Biotechnology (Houston, TX, USA). Anti-p-Akt antibodies were obtained from Santa Cruz Biotechnology (Santa Cruz, CA, USA). Anti- $\beta$-actin antibody, Glucose oxidase (GOX) and other chemicals were purchased from Sigma (St. Louis, MO, USA).

\section{Cell culture}

B35 neuroblastoma cells were purchased from American Type Culture Collection (Manassas, VA, USA). For all experiments, cells were grown in DMEM supplemented with $100 \mathrm{U} /$ $\mathrm{ml}$ penicillin, $0.1 \mathrm{mg} / \mathrm{ml}$ streptomycin and $10 \%$ heat inactivated FBS in culture plates. The cells were incubated in a $37^{\circ} \mathrm{C}$ incubator under $5 \% \mathrm{CO}_{2}$ in a humidified atmosphere. After reaching confluence, cells were pretreated with various drugs depending on the experimental design.

\section{Detection of LDH activity}

Cell viability changes due to GOX and culture conditions were determined in terms of LDH released into media of cell cultures. Cells in the exponential phase of growth were seeded at $1 \times 10^{4}$ cells/well in 24-well plates. After different treatments, $50 \mathrm{ml}$ of standards or $50 \mathrm{ml}$ of culture supernatant (controls and treated cells) and $50 \mathrm{ml}$ of substrate mix were transferred into a 96-well-plate. After incubation for $30 \mathrm{~min}$ at room temperature, plates were read using a SUNRISE ELISA-plate Reader (Tecan, Crailsheim, Germany) at $490 \mathrm{~nm}$. LDH released from cells is expressed as a percentage of total cellular LDH.

\section{Western blot analysis}

Whole cell lysates were isolated using PRO-PREP protein extract solution. The whole cell lysates were centrifuged at $100,000 \mathrm{~g}$ for $20 \mathrm{~min}$ at $4^{\circ} \mathrm{C}$. The protein concentration in each lysate was determined by the Bradford assay. To detect Aktphosphorylation, 30 micrograms of protein were subjected to $10 \%$ SDS-polyacrylamide gel electrophoresis for $90 \mathrm{~min}$ at 120 $\mathrm{V}$ depending on the molecular size of the phospho-Akt protein. The separated proteins were transferred to polyvinylidene difluoride (PVDF) membranes for $2 \mathrm{~h}$ at $20 \mathrm{~mA}$ using SD Semidry Transfer Cells (Bio-Rad Laboratories, Hercules, CA, USA). 
The membranes were stained with Ponceau S solution to determine efficiency of transfer and/or protein loading levels. Then the PVDF membranes were blocked for $2 \mathrm{~h}$ at room temperature with $5 \%$ nonfat milk in Tris-buffed saline (TBS, $\mathrm{pH}$ 7.0) containing $0.05 \%$ Tween 20 (TBS-T). The membranes were incubated with an anti-phospho-Akt antibody overnight at $4^{\circ} \mathrm{C}$, using a dilution of $1: 500$ in $5 \%$ bovine serum albumin (BSA) in TBS-T. For the detection of bound antibody, horseradish peroxidase conjugated anti-goat or anti-rabbit IgG was used. The signals were detected by ECL using a western blotting luminol reagent system (iNtRON Biotechnology, Houston, TX, USA) and autoradiography.

\section{FACS analysis}

A total of $1 \times 10^{7}$ cells were seeded in $100 \mathrm{~mm}$ culture dishes, incubated at $37^{\circ} \mathrm{C}$, and harvested at the indicated times after mitosis. Cells were stained with propidium iodide (PI) using a previously described method [8]. The harvested cells were trypsinized, washed twice in PBS, and fixed in $70 \%$ ethanol on ice for a minimum of $2 \mathrm{~h}$. Cells were washed 2 additional times with PBS and stained for $30 \mathrm{~min}$ at $37^{\circ} \mathrm{C}$ in $50 \mu \mathrm{g} / \mathrm{ml} \mathrm{PI}$ solution containing $200 \mu \mathrm{g} / \mathrm{ml}$ RNase A and $0.1 \%$ Triton X-100. After incubation of samples in the dark for 30 minutes, cell cycle profiles were determined using a Beckton-Dickinson flow cytometer (Becton Dickenson Biosciences, San Jose, CA, USA) with CellQuest ${ }^{\circledR}$ Software.

A

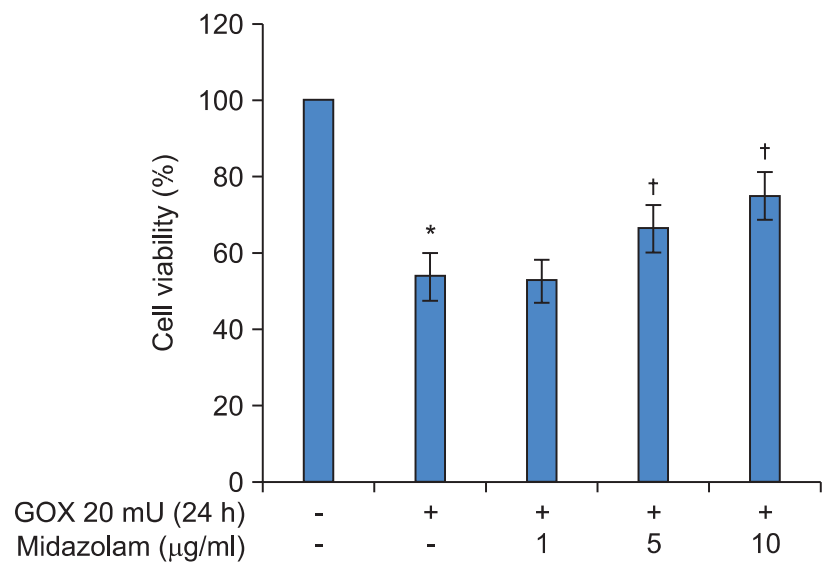

\section{Statistical analysis}

Values are expressed as means \pm SD. Differences between data sets were assessed by one-way analysis of variance (ANOVA) followed by the Newman-Keuls test. $\mathrm{P}<0.05$ was regarded as statistically significant.

\section{Results}

\section{Akt phosphorylation is responsible for the protective effect of midazolam against ROS damage}

The effects of midazolam on cell viability during ROS injury were analyzed by LDH assay. As expected, $10 \mathrm{~h}$ of incubation with $20 \mathrm{mU} / \mathrm{ml}$ of GOX significantly decreased cell viability. Fig. 1A shows that GOX derived ROS injury decreased cell viability about 1.6-2 times compared to the control. However, treatment with midazolam (5 and $10 \mu \mathrm{g} / \mathrm{ml}$ ) concentration-dependently reduced the decreased cell viability due to ROS injury, and this difference was statistically significant. To determine the effect of an Akt-phosphorylation inhibitor on cell viability, $5 \mu \mathrm{M}$ concentrations of LY294002 were used to treat cells for $1 \mathrm{~h}$ prior to treatment with midazolam. As shown in Fig. 1B, LY294002 inhibited the protective effect of midazolam. For example, pretreatment with $5 \mu \mathrm{M}$ LY294002 significantly decreased cell viability that had been induced by midazolam.

B

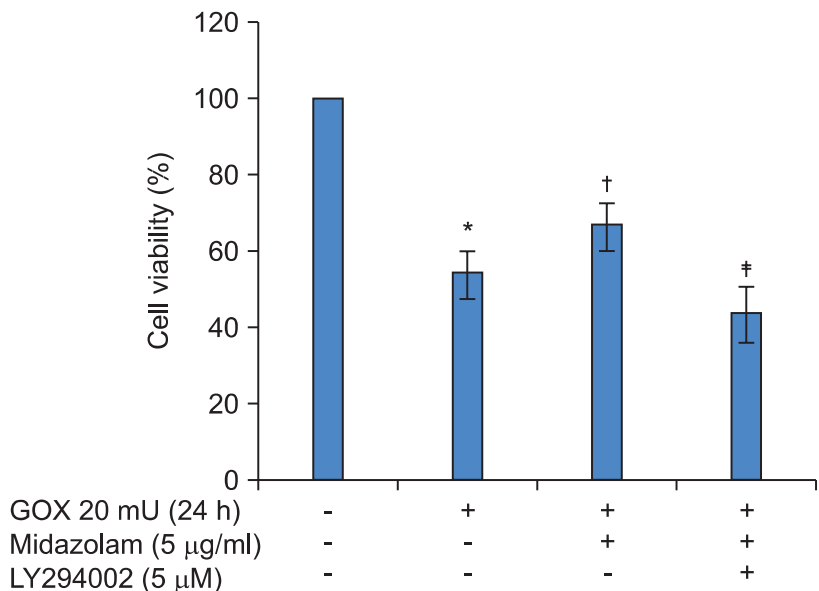

Fig. 1. The Cytoprotective effect of midazolam on GOX (Glucose Oxidase) derived ROS injury in B35 rat neuroblastoma cells. (A) The cytoprotective effect of midazolam against ROS derived cell death was measured by LDH production. Cells were pretreated with different concentrations of midazolam for $8 \mathrm{~h}$, and then exposed to $20 \mathrm{mU} / \mathrm{ml}$ of GOX for $10 \mathrm{~h}$. (B) The protective effect of midazolam against ROS injury was diminished by treatment with LY294002. Pretreatment of LY294002 $(5 \mu \mathrm{M})$ was done during $1 \mathrm{~h}$ before incubation of cells with $5 \mu \mathrm{g} / \mathrm{ml}$ of midazolam for $8 \mathrm{~h}$. Thereafter, cells were exposed to $20 \mathrm{mU} / \mathrm{ml}$ of GOX for $10 \mathrm{~h}$. Data represent means $\pm \mathrm{SD}$ of three independent experiments $(* \mathrm{P}<$ 0.01 , compared with the control, ${ }^{\dagger} \mathrm{P}<0.01$, compared with GOX derived ROS injury, ${ }^{\dagger} \mathrm{P}<0.01$, compared with midazolam). 


\section{Dose-dependent induction of Akt-phosphorylation by midazolam is mediated through PI3 kinase activation}

We next asked whether midazolam can protect B35 cells from oxidative stress induced injury by regulating Akt-phos-

A

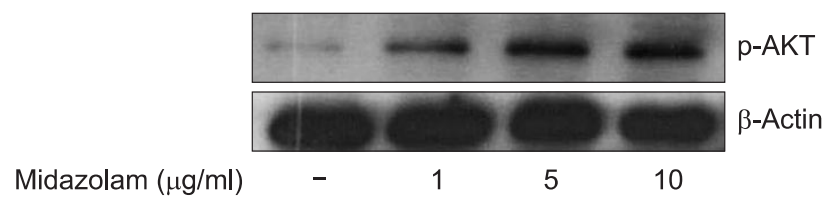

phorylation. Akt phosphorylation plays important roles in general cellular defense systems against oxidative stress in mammalian cells. As shown in Fig. 2, western blot analysis indicated that midazolam-induced cytoprotective effects in ROS injury may be mediated by induction of Akt-phosphorylation

B

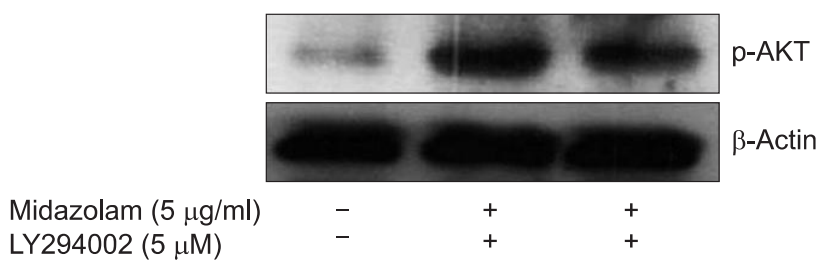

Fig. 2. PI3K-dependent Akt-phosphorylation mediated by midazolam in B35 neuroblastoma cells. (A) The upper panel shows that midazolam increases levels of phosphorylated-Akt protein in a concentration-dependent manner. After treatment with the indicated concentrations of midazolam for $8 \mathrm{~h}$, western blotting was performed. (B) The upper panel shows that midazolam induced phospho-Akt protein expression was diminished by LY-294002, an inhibitor of PI3 kinase. The indicated concentrations of the PI3 kinase inhibitor, LY-294002, were added 30 min prior to midazolam, and western blotting was performed after an $8 \mathrm{~h}$ incubation.

A

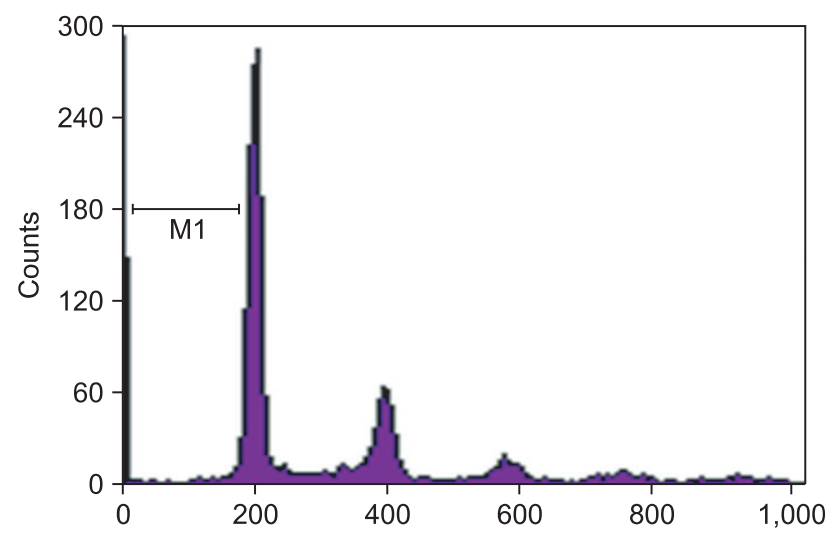

C

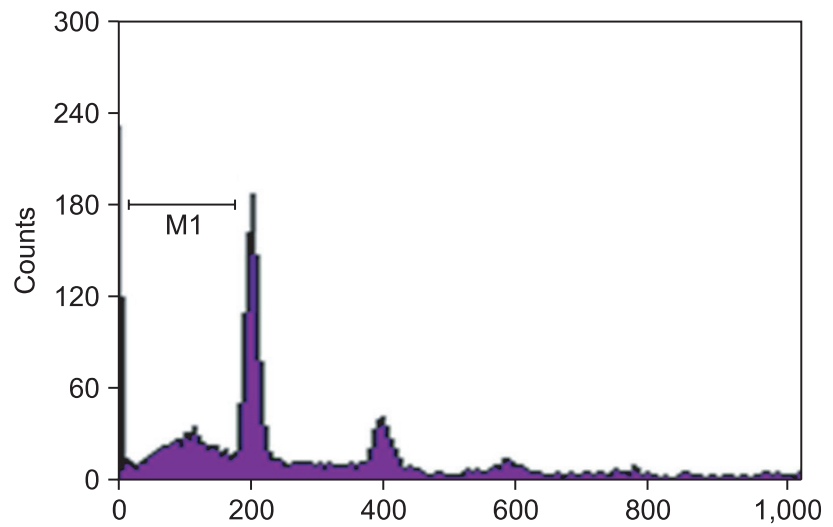

B

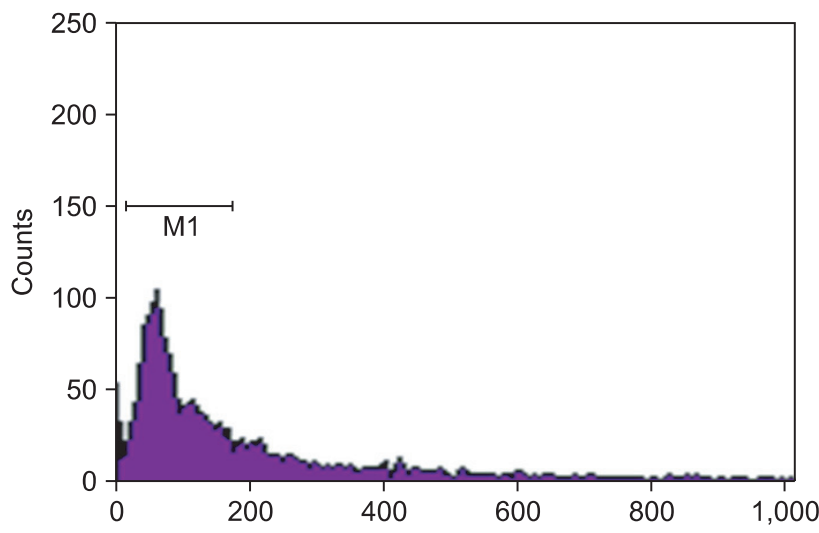

D

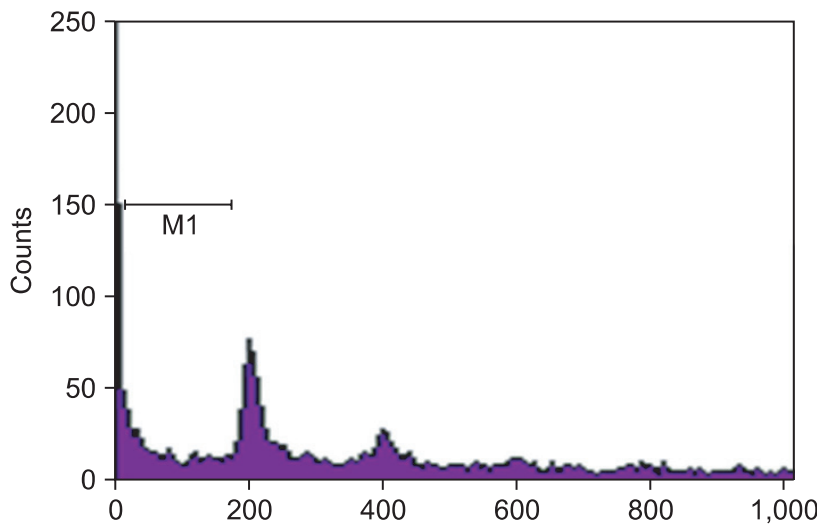

Fig. 3. Akt-phosphorylation mediates the cytoprotective effect of midazolam against GOX-induced apoptosis. A fixed concentration of GOX $(20 \mathrm{mU} / \mathrm{ml})$ was used along with midazolam $(5 \mu \mathrm{g} / \mathrm{ml})$ with/without LY-294002 $(5 \mu \mathrm{M})$. After a $10 \mathrm{~h}$ incubation with only GOX, FACS analysis was performed. (A) Under no pretreatment, apoptosis was not significant. (B) Apoptosis was induced by GOX. (C) When cells were pretreated with midazolam for $8 \mathrm{hrs}$ before GOX treatment, apoptosis was diminished. (D) The anti-apoptotic effect of midazolam was abolished by cotreatment with LY-294002. 
through PI3 kinase activation. The effect of midazolam on Akt-phosphorylation was dose dependent, but the induction was abolished by pretreatment with LY294002, a PI3 kinase inhibitor.

\section{Midazolam inhibits GOX-induced apoptosis through Akt phosphorylation}

It is generally known that ROS induces apoptosis in many mammalian cells [9] and GOX is frequently used as a chronic ROS producing agent [10]. Therefore, we investigated whether midazolam protects cells from GOX-induced apoptosis. Fig. 3 shows that GOX-induced apoptosis was diminished by midazolam pretreatment. The effect is mediated through Aktphosphorylation because the diminished apoptosis due to addition of midazolam became obvious again as the concentration of LY294002, an inhibitor of PI3 kinase, increased. FACS analysis (Fig. 3) showed that about $61 \%$ of cells underwent apoptosis after GOX (20 U/ml), but pretreatment with midazolam significantly reduced the fraction of dead cells to $21 \%$. Co-treatment with LY294002 significantly reduced the anti-apoptotic effect of midazolam.

\section{Discussion}

The major finding of this study is that the midazolam increases Akt phosphorylation through PI3 kinase activation and significantly decreases GOX-induced apoptotic cell death in B35 cells. This conclusion is based on the findings that: (1) midazolam concentration-dependently induces phosphorylation of Akt in B35 cells; (2) LY-294002, a PI3 kinase inhibitor, significantly inhibits the protective effect of midazolam against ROS injury.

For application of the results of the present study to an in vivo study, pharmacological concentrations have to be considered. The concentrations used $(1,5$ and $10 \mu \mathrm{g} / \mathrm{ml})$ in the present study were chosen based on the report of Hudson [11]. In the report, midazolam was given to patients with abdominal aortic surgery at $0.25 \mathrm{mg} / \mathrm{kg}$ and the maximum plasma concentration $\left(C_{\text {max }}\right)$ ranged from 200 to $3,000 \mathrm{ng} / \mathrm{ml}$. Several studies reported that midazolam has antioxidant effects, and these effects could make midazolam effective against pathologic states mediated by oxidative stresses $[5,6]$. Interestingly, the findings in this study indicate that the beneficial effects of midazolam on ROSinduced pathologic states may also be regulated by induction of protective mechanisms such as Akt-phosphorylation.

However, the finding in the present study does not coincide with the study of Stevens et al. [12]. They reported pro-apoptotic effects of midazolam in human Jurkat T-lymphoma cells and human neuroblastoma cells via regulation of mitochondrial pathways at midazolam concentrations ranging from 100 to $400 \mu \mathrm{M}$ (over $24 \mathrm{hr}$ ). These finding are not consistent with results of the present study, but this could be because several factors in the two studies were different. We exposed cells for only $8 \mathrm{hrs}$. The concentrations of midazolam and the duration of the pre-incubation step were different. In the present study, we used midazolam concentrations of 1,5 and $10 \mu \mathrm{g} /$ $\mathrm{ml}$ which correspond, respectively, to $0.31 \mu \mathrm{M}(1 \mu \mathrm{g} / \mathrm{ml}), 1.53$ $\mu \mathrm{M}(5 \mu \mathrm{g} / \mathrm{ml})$ and $3.1 \mu \mathrm{M}(10 \mu \mathrm{g} / \mathrm{ml})$. Thus, midazolam may induce apoptosis at higher concentrations that are more toxic concentration but this has to be evaluated further to confirm that midazolam has dual effects on apoptosis depending on its concentration.

Generally, it is well-recognized that Akt-phosphorylation plays a major role in cell proliferation and survival in many cell types and is classically activated by phosphoinositidedependent kinases following recruitment to the plasma membrane by products of the type I phosphoinositide 3-kinase [13]. However, the fact that midazolam may serve a critical role in a cell's protective mechanism during oxidative stress through Akt phosphorylation is a novel finding.

Originally, this exploratory study was done to determine whether midazolam can protect cells from soman induced neural injury. Because ROS are involved in the neurotoxicity or neuronal injury during soman intoxication [14,15], we deliberately used $20 \mathrm{mU} / \mathrm{ml}$ GOX to simulate a pathologic state where the generation of sustained and continual release of $\mathrm{H}_{2} \mathrm{O}_{2}$ can give rise to oxidative stress [16]. Therefore, the antiapoptotic effect of midazolam in GOX-induced ROS injury supports the idea that midazolam has a beneficial effect in soman intoxication.

In summary, we showed that midazolam, a benzodiazepine, leads to phosphorylation of Akt in neuronal cells through activation of the $\mathrm{PI}_{3}$ kinase pathway. This induction of Aktphosphorylation is responsible for the protection of B35 cells from GOX-induced oxidative stress. Thus, we conclude that midazolam is important in the management of soman-induced neuronal injury.

\section{Acknowledgements}

This work was supported in part by Konyang University Myunggok Research Fund 2007.

\section{References}

1. McDonough JH Jr, Dochterman LW, Smith CD, Shih TM. Protection against nerve agent-induced neuropathology, but not cardiac pathology, is associated with the anticonvulsant action of drug treatment. Neurotoxicology 1995; 16: 123-32. 
2. Prindull G. Apoptosis in the embryo and tumorigenesis. Eur J Cancer 1995; 31A: 116-23.

3. Matés JM, Sánchez-Jiménez FM. Role of reactive oxygen species in apoptosis: implications for cancer therapy. Int J Biochem Cell Biol 2000; 32: 157-70.

4. Goode HF, Cowley HC, Walker BE, Howdle PD, Webster NR. Decreased antioxidant status and increased lipid peroxidation in patients with septic shock and secondary organ dysfunction. Crit Care Med 1995; 23: 646-51.

5. Weinbroum AA, Halpern P, Rudick V, Sorkine P, Freedman M, Geller E. Midazolam versus propofol for long-term sedation in the ICU: a randomized prospective comparison. Intensive Care Med 1997; 23: 1258-63.

6. Wilms H, Claasen J, Röhl C, Sievers J, Deuschl G, Lucius R. Involvement of benzodiazepine receptors in neuroinflammatory and neurodegenerative diseases: evidence from activated microglial cells in vitro. Neurobiol Dis 2003; 14: 417-24.

7. Kang MY, Tsuchiya M, Packer L, Manabe M. In vitro study on antioxidant potential of various drugs used in the perioperative period. Acta Anaesthesiol Scand 1998; 42: 4-12.

8. Nizamutdinova IT, Lee GW, Son KH, Jeon SJ, Kang SS, Kim YS, et al. Tanshinone I effectively induces apoptosis in estrogen receptorpositive (MCF-7) and estrogen receptor-negative (MDA-MB-231) breast cancer cells. Int J Oncol 2008; 33: 485-91.
9. Park MK, Kim WS, Lee YS, Kang YJ, Chong WS, Kim HJ, et al. Glucose oxidase/glucose induces apoptosis in C6 glial cells via mitochondria-dependent pathway. J Appl Pharmacol 2005; 13: 20713.

10. Simon HU, Haj-Yehia A, Levi-Schaffer F. Role of reactive oxygen species (ROS) in apoptosis induction. Apoptosis 2000; 5: 415-8.

11. Hudson RJ. Midazolam pharmacokinetics in patients undergoing abdominal aortic surgery. Anesth Analg 1994; 79: 219-25.

12. Stevens MF, Werdehausen R, Gaza N, Hermanns H, Kremer D, Bauer I, et al. Midazolam activates the intrinsic pathway of apoptosis independent of benzodiazepine and death receptor signaling. Reg Anesth Pain Med 2011; 36: 343-9.

13. Vanhaesebroeck B, Alessi DR. The PI3K-PDK1 connection: more than just a road to PKB. Biochem J 2000; 346: 561-76.

14. Jacobsson SO, Cassel GE, Persson SA. Increased levels of nitrogen oxides and lipid peroxidation in the rat brain after soman-induced seizures. Arch Toxicol 1999; 73: 269-73.

15. Pazdernik TL, Nelson SR, Cross R, Samson FE. Chemical inducedseizures: free radicals as a final common pathway. Proc Med Def Biosci Rev 1996; 1: 413-22.

16. D'Agnillo F, Alayash AI. A role for the myoglobin redox cycle in the induction of endothelial cell apoptosis. Free Radic Biol Med 2002; 33: 1153-64. 